\title{
Too many ends: aberrant transposition
}

\author{
Clifford F. Weil ${ }^{1}$ \\ Agronomy Department, Purdue University, West Lafayette, Indiana 47907, USA
}

\begin{abstract}
A recent study by Zhang and colleagues published in the March 15, 2009, issue of Genes \& Development (pp. 755765) demonstrates that maize $A c / D s$ transposons mediate translocations and other rearrangements through aberrant execution of the normal transposition process. Ac transposase uses one end from each of two neighboring elements in these events, which may happen more commonly than previously thought. In genomes where there can be many transposon ends scattered across all the chromosomes, such mistakes can have important consequences.
\end{abstract}

The dynamic nature of genomes is now an accepted fact of biology, with transposon movement and rearrangement of chromosomes taught even to high school biology classes. Translocations, inversions, and duplications have been important genetic tools in a wide range of organisms for almost a century. In many cases, these rearrangements arise spontaneously after double-stranded breaks in DNA, and a significant cause of these breaks is transposition by mobile DNA elements.

One of the earliest observations McClintock (1948) made in her discovery of transposable elements was that, in addition to their movement, these elements had the ability to cause cytologically detectable chromosome rearrangement. Once molecular tools were well established, papers began to emerge in both the plant and animal transposon literature clearly placing transposons at chromosomal rearrangement break points. More recently, similar rearrangements have been reported among fungal transposons as well (Hua-Van et al. 2002).

The high copy number of transposons and their distribution throughout the genome suggest that one mechanism for these rearrangements is recombination. In the larger context of genome evolution, a great deal of interest has long been placed on the role of repetitive DNA elements such as transposons (for a recent review, see Bennetzen 2005). These sequences permit unequal crossover, establish blocks of tightly linked genes that become inherited as groups, and may even establish centromeres and telomeres (Carbon and Clarke 1990; Richards et al. 1991).

[Keywords: V(D)J recombination; chromosome rearrangements; hAT elements; transposition]

${ }^{1}$ Correspondence.

E-MAIL cweil@purdue.edu; FAX (765) 496-2926.

Article is online at http://www.genesdev.org/cgi/doi/10.1101/gad.1801309.
However, an alternative mechanism for mediating rearrangement is that transposition mechanisms are directly responsible for the breakage and eventual rejoining of the DNA in these rearrangements, with the idea that some form of aberrant transposition had occurred. Some recent work, including a paper published in the March 15, 2009, issue of Genes \& Development (Zhang et al. 2009), has also been examining mechanistic roles for how transposons may mediate rearranging genomes all by themselves, simply as a by-product of their normal function.

\section{Transposases and transposon ends}

For eukaryotic transposons that move via DNA intermediates (Type II elements), there are often subtle differences between the sequences at each end of a transposon that distinguish them and, in some instances, transposase enzymes bind each of them differentially (for review, see Kunze and Weil 2002). A typical transposition event has transposase complexes bound to a "left" end and a "right" end of the same mobile element (Fig. 1A). This defines the boundaries of the element, and the two ends synapse and act together in transposition. Ordinarily, the transposase cuts the ends of the transposon, freeing the transposon to be joined to some new insertion site. As the transposon inserts at its new location, staggered, single-stranded nicks in the target are created, the transposon is joined to the protruding ends of the new site, and the gaps are filled in to create a short duplication of the target site sequence adjacent to both ends of the transposon. This characteristic target site duplication (TSD) immediately flanking the insertion site differs in length depending on the transposon family. It is likely, though not yet demonstrated, that transposase molecules holding the ends of the transposon in a specific configuration when it attempts to reinsert are responsible for just how far apart the single-strand nicks are and, therefore, how large the TSDs are. Typically, the site from which the transposon was excised is repaired either by nonhomologous endjoining (NHEJ) or by using a homologous and unbroken DNA such as a sister chromatid or homologous chromosome as a template (for review, see Kunze and Weil 2002).

Transposons propagate by transposing and it is thus vital to their survival that individual elements are recognizable as such to the enzyme that moves them. However, given that many transposons exist in copy numbers ranging up to tens of thousands, there are large numbers of element ends at various places throughout the 


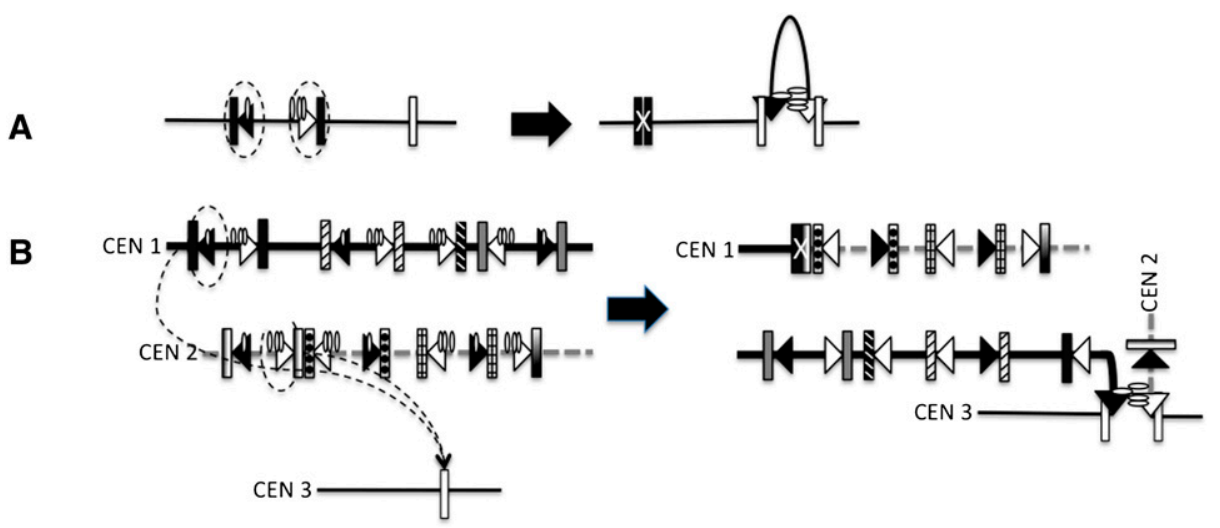

Figure 1. Ac/Ds transposition, right and wrong. $(A)$ Diagram of a single transposon moving. Different ends of the element are indicated as filled and open triangles, transposase molecules are shown as open ovals, and target site and TSDs are indicated as vertical rectangles. Transposase molecules bound at the two ends, indicated by dotted circles, interact to facilitate transposition. Upon reinsertion, a new TSD is created. Note that the transposon can reinsert in either orientation (filled triangle at left, as shown, or filled triangle at right). Excision site is repaired by error-prone, NHEJ of TSDs, indicated by X. (B) Aberrant transposition in a genome with numerous transposons and partial transposons. Each insertion has its own TSD, represented by different vertical rectangles. Three chromosomes are shown as a heavy line, a dashed line, and a thin solid line, each with its centromere. Transposase binds at numerous ends throughout the genome, and interaction can occur between two ends (dotted circles) that are not part of the same transposon. Transposition events and repair of excision sites can lead to translocations (shown); "reinsertion" in the opposite orientation (filled triangle on the right), would be a dicentric chromosome (CEN2/CEN3) and an acentric fragment.

genomes and in all possible orientations and distances relative to one another. Defining a single element (one left end and one right end in the correct relative orientations) can thus be a challenge.

\section{When transposases make mistakes}

Initial binding of transposase to one transposon end as compared with the other end of the same element proves to be surprisingly independent. As a result, as much as $20 \%$ of the time, transposase bound to an end from one element can interact with transposase bound to an end of a second, nearby element, leading to an aberrant transposition event (Fig. 1B). However, in such cases what is being "excised" and "reinserted" is not a typical transposon at all but a region of chromosomal DNA. Depending on what is to be reinserted and where, rearrangements such as duplications, deficiencies, inversions, and translocations can result. Indeed, this same sort of interaction between ends of different transposons and aberrant transposition lies at the heart of the chromosome breakage that allowed McClintock (1948) to recognize the element she named Dissociation (Ds) when she first described transposable elements. The molecular explanation of the dicentric chromosome leading to the bridge-breakagefusion cycles that identified $D s$ proved to be the cell repairing an "excision" event that involved two different elements, each on different sister chromatids (English et al. 1993; Weil and Wessler 1993). Repair of the "excision site" by NHEJ fuses the sister chromatids. When the centromeres attached to these sister chromatids go to separate poles at the next mitosis, an anaphase bridge is formed.

This proves to be only the tip of a proverbial iceberg of rearrangements these elements can produce. Each involves either transposition of only one end of a transposon instead of both (seen for the $A c$ relative in snapdragon, Tam3) (Hudson et al. 1990), or the combined use of two transposon ends that each belongs to separate transposons (Doring et al. 1985, 1989; Ralston et al. 1989; English et al. 1993, 1995; Weil and Wessler 1993; Zhang and Peterson 1999, 2004; Huang and Dooner 2008). Without postulating any change in the mechanisms of cutting and rejoining, these alternative scenarios explain many of the rearrangements seen. Note that there are two DNA joining events in the process-insertion of the "transposon" at its new location and repair of the "excision site" the transposon has left—and both provide opportunity to form novel chromosomes or initiate bridge-breakage-fusion cycles that can lead to further rearrangements. For example, transposase bound to one end of an Ac element and to a partial or "fractured" $A c$ $>30 \mathrm{~kb}$ away and in the same relative orientation also causes chromosome breakage, even though the transposons are likely to be on the same sister chromatid (Ralston et al. 1989). Similarly, for two Ds elements near each other and in the same relative orientation, transposase-dependent deletions of all the sequences between the transposons suggest that such events occur by the formation of large "macrotransposons" that carry with them all the chromosomal DNA between the mobile element ends, similar to the compound transposons flanked by IS elements observed in bacterial systems (Klein et al. 1988; Dowe et al. 1990). The closer together the individual elements are, the more likely they are to move in concert as a macrotransposon (Dooner and Belachew 1991). Dooner and coworkers (Huang and Dooner 2008) confirmed recently that one such macrotransposon in maize both excises and reinserts, and found that in doing so it can create deletions, inversions, and 
other more complex rearrangements. Depending on the combination of ends used, the position of the reinsertion site relative to the centromere, and whether or not the new site has been replicated, the aberrant use of transposon ends becomes a potent source of genome restructuring.

\section{Transposase-mediated chromosome rearrangement}

Following up on several years of work looking at aberrant transposition events of maize $A c / D$ s transposons (Zhang and Peterson 1999, 2004, 2005; Zhang et al. 2006), Peterson and colleagues reported in the March 15, 2009, issue of Genes \& Development (Zhang et al. 2009) that aberrant transpositions for these elements are, perhaps, more common than was thought previously and have the potential to be a major force in genome evolution. Zhang et al. (2009) show quite convincingly that rearrangements using transposon ends from different elements are likely to be formed using the same steps as transposition events. This similarity includes the creation of the same 8-base-pair TSDs on either side of the rearrangement break points that are seen flanking normal $A c / D s$ transposon insertions. While this might not seem surprising in retrospect, it had never been demonstrated as a regular feature of transposon-associated rearrangements and argues that the rearrangements occur by aberrant transposition and not recombination.

Successful movement of single elements can place copies of mobile elements near one another in the genome and create powerful and lasting pathways in which genomes can rearrange, mix novel sets of genes into new linkage groups, and potentially create new genes. Peterson's group (Zhang et al. 2009) points out, as have others before them, that this is especially true for a transposon like $A c / D s$, which reinserts predominantly at linked sites. What we now have to consider more carefully is that these linked transposons not only create sites for potential unequal crossover and other sorts of recombination-mediated rearrangement, but quickly create multiple combinations of available transposon ends. The bursts of transposition by various elements that are thought to have punctuated evolution thus may have created havoc very quickly, creating hundreds, if not thousands of rearrangement break points. One can imagine fairly rapid reproductive isolation (parents from progeny and progeny from each other) during such times, leading to adaptive radiation and speciation. Epigenetic control mechanisms that keep transposons silent in eukaryotic genomes may have arisen as much to counter this more immediate threat as they did to prevent insertional inactivation of essential genes.

\section{Interesting consequences of aberrant transposition}

Transposase use of mismatched ends (at least from the transposon's point of view) is not restricted to plant transposons. Drosophila P elements have been observed to create similar rearrangements when $\mathrm{P}$ transposase binds ends of different elements and tries to transpose them together (Delattre et al. 1995; Gray et al. 1996). Recent reports observed that the Drosophila genome appears to be particularly prone to rearranging when different species are compared (Ranz et al. 2001). However, this "malleability" of the Drosophila genome when comparing Drosophila species has not been accompanied by a high degree of transposition by individual genes (Ranz et al. 2003). Rather, gene movement tends to be as blocks of genes, a mechanism suggesting that larger-scale rearrangement is a more common occurrence than transposons flanking a single gene or gene fragment and moving it to a new location. It is worth mentioning that maize, which also has a large number of transposon ends and active transposases, also shows a very "malleable" genome, when comparing maize inbred lines (Fu and Dooner 2002; Brunner et al. 2005; Messing and Dooner 2006; Wang and Dooner 2006; Huang and Dooner 2008). Similar to the Drosophila comparison, blocks of genes are often rearranged and transposons very likely play a role in that, moving chromosome segments as described by Zhang et al. (2009) and others, and through moving fragments, such as has been observed for Helitrons (Lal et al. 2003; Lai et al. 2005; Morgante et al. 2005; Du et al. 2008).

In addition, some organisms may have adapted these rearrangement mechanisms to carry out important functions, leading in turn to further, interesting adaptations within the organisms (for a recent review, see Feschotte and Pritham 2007). The most intensively studied of these are immunoglobulin gene rearrangements in vertebrates, or "V(D)J recombination" (for review, see Schatz 2004; Soulas-Sprauel et al. 2007). In this system, a large piece of DNA is removed from between gene segments that are then ligated together to create genes for immune receptors. The process resembles excision by the transposon family containing $A c / D s$ mechanistically, and the enzyme responsible as well as its binding sites resemble the transposase and transposon ends of Transib elements (Coen et al. 1989; Weil and Kunze 2000; Zhou et al. 2004). Furthermore, the DNA excised from between the immune receptor gene fragments can occasionally reinsert elsewhere in the genome (Neiditch et al. 2002). This would-be (or used-to-be) transposon also has its share of aberrant transposition, just as the systems already discussed. Ordinarily, the ends of the excised DNA in $\mathrm{V}(\mathrm{D}) \mathrm{J}$ rearrangement are fused together into a "signal joint" and cannot attack a new target site, but reinsertion can occur when signal joint formation fails. When one signal end remains attached to its original position while the other is free to fuse with a new site, like the Tam3 case mentioned earlier, the result is a translocation. A variety of diseases, such as lymphoblastic leukemias and follicular lymphoma, are precisely these fusions of immune receptor gene loci (and promoters) to ectopic genes in various parts of the genome (for examples, see Marculescu et al. 2006). Interestingly, DNA-PK $\mathrm{cs}_{\text {, }}$ one of the important enzymes required for signal joint formation (Fukumura et al. 2000), is unique to vertebrates, raising the intriguing possibility that its role in the $\mathrm{V}(\mathrm{D}) \mathrm{J}$ process evolved, in part, to prevent transposition-like misadventures from happening. 
On a wider scale than just aberrations in $\mathrm{V}(\mathrm{D}) \mathrm{J}$ joining, recent studies suggest that genome rearrangement and copy number variation (CNV) may outstrip nucleotide variation as a cause underlying genetic disease in humans (Lee and Lupski 2006; Lupski 2007). Aberrant transposition is clearly not at the root of all these rearrangements, but the recent studies in maize, an organism with fewer repetitive transposon ends but where the transposase that binds them is still active, remind us that even low levels of transposition can have important consequences in a genome littered with transposon ends.

\section{Acknowledgments}

I acknowledge Heather Cosel-Pieper and Terri Grodzicker for helpful suggestions on the manusript. I am supported by grants from the National Science Foundation.

\section{References}

Bennetzen, J.L. 2005. Transposable elements, gene creation and genome rearrangement in flowering plants. Curr. Opin. Genet. Dev. 15: 621-627.

Brunner, S., Fengler, K., Morgante, M., Tingey, S., and Rafalski, A. 2005. Evolution of DNA sequence nonhomologies among maize inbreds. Plant Cell 17: 343-360.

Carbon, J. and Clarke, L. 1990. Centromere structure and function in budding and fission yeasts. New Biol. 2: 10-19.

Coen, E.S., Robbins, T.P., Almeida, J., Hudson, A., and Carpenter, R. 1989. Consequences and mechanisms of transposition in Antirrhinum majus. In Mobile DNA (eds. D.E. Berg and M.M. Howe), pp. 413-436. American Society for Microbiology, Washington, DC.

Delattre, M., Anxolabehere, D., and Coen, D. 1995. Prevalence of localized rearrangements vs. transpositions among events induced by Drosophila P element transposase on a P transgene. Genetics 141: 1407-1424.

Dooner, H.K. and Belachew, A. 1991. Chromosome breakage by pairs of closely linked transposable elements of the $A c-D s$ family in maize. Genetics 129: 855-862.

Doring, H.-P., Garber, R., Nelsen, B., and Tillmann, E. 1985. Transposable element $D s$ and chromosomal rearrangements. In Plant genetics (ed. M. Freeling), pp. 335-367. Alan R. Liss, New York.

Doring, H.P., Nelsensalz, B., Garber, R., and Tillmann, E. 1989. Double $D$ s elements are involved in specific chromosome breakage. Mol. Gen. Genet. 219: 299-305.

Dowe Jr., M.F., Roman, G.W., and Klein, A.S. 1990. Excision and transposition of two Ds transposons from the bronze mutable 4 derivative 6856 allele of Zea mays L. Mol. Gen. Genet. 221: 475-485.

Du, C., Caronna, J., He, L., and Dooner, H.K. 2008. Computational prediction and molecular confirmation of Helitron transposons in the maize genome. BMC Genomics 9: 51 . doi: 10.1186/1471-2164-9-51.

English, J., Harrison, K., and Jones, J.D.G. 1993. A Genetic analysis of the DNA requirements for Dissociation state I activity in tobacco. Plant Cell 5: 501-514.

English, J.J., Harrison, K., and Jones, J.D.G. 1995. Aberrant transpositions of maize double Ds-like elements usually involve Ds ends on sister chromatids. Plant Cell 7: 12351247.

Feschotte, C. and Pritham, E.J. 2007. DNA transposons and the evolution of eukaryotic genomes. Annu. Rev. Genet. 41: 331368.
$\mathrm{Fu}, \mathrm{H}$. and Dooner, H.K. 2002. Intraspecific violation of genetic colinearity and its implications in maize. Proc. Natl. Acad. Sci. 99: 9573-9578.

Fukumura, R., Araki, R., Fujimori, A., Tsutsumi, Y., Kurimasa, A., Li, G.C., Chen, D.J., Tatsumi, K., and Abe, M. 2000. Signal joint formation is also impaired in DNA-dependent protein kinase catalytic subunit knockout cells. J. Immunol. 165: 3883-3889.

Gray, Y.H.M., Tanaka, M.M., and Sved, J.A. 1996. P-elementinduced recombination in Drosophila melanogaster: Hybrid element insertion. Genetics 144: 1601-1610.

Hua-Van, A., Langin, T., and Daboussi, M.J. 2002. Aberrant transposition of a Tc1-mariner element, impala, in the fungus Fusarium oxysporum. Mol. Genet. Genomics 267: 79-87.

Huang, J.T. and Dooner, H.K. 2008. Macrotransposition and other complex chromosomal restructuring in maize by closely linked transposons in direct orientation. Plant Cell 20: 2019-2032.

Hudson, A.D., Carpenter, R., and Coen, E.S. 1990. Phenotypic effects of short-range and aberrant transposition in Antirrhinum majus. Plant Mol. Biol. 14: 835-844.

Klein, A.S., Clancy, M., Paje-Manalo, L., Furtek, D., Hannah, L.C., and Nelson, O.E. 1988. The mutation bronze-mutable 4 derivative 6856 in maize is caused by the insertion of a novel 6.7-kilobase pair transposon in the untranslated leader region of the bronze-1 gene. Genetics 120: 779-790.

Kunze, R. and Weil, C.F. 2002. The hAT and CACTA superfamilies of plant transposons. In Mobile DNA II (eds. N.L. Craig et al.), pp. 565-610. ASM Press, Washington, DC.

Lai, J., Li, Y., Messing, J., and Dooner, H.K. 2005. Gene movement by Helitron transposons contributes to the haplotype variability of maize. Proc. Natl. Acad. Sci. 102: 9068 9073.

Lal, S.K., Giroux, M.J., Brendel, V., Vallejos, C.E., and Hannah, L.C. 2003. The maize genome contains a helitron insertion. Plant Cell 15: 381-391.

Lee, J.A. and Lupski, J.R. 2006. Genomic rearrangements and gene copy-number alterations as a cause of nervous system disorders. Neuron 52: 103-121.

Lupski, J.R. 2007. Genomic rearrangements and sporadic disease. Nat. Genet. 39: S43-S47. doi: 10.1038/ng2084.

Marculescu, R., Vanura, K., Montpellier, B., Roulland, S., Le, T., Navarro, J.M., Jager, U., McBlane, F., and Nadel, B. 2006. Recombinase, chromosomal translocations and lymphoid neoplasia: Targeting mistakes and repair failures. DNA Repair (Amst.) 5: 1246-1258.

McClintock, B. 1948. Mutable loci in maize. Carnegie Inst Washington Yearb 47: 155-169.

Messing, J. and Dooner, H.K. 2006. Organization and variability of the maize genome. Curr. Opin. Plant Biol. 9: 157-163.

Morgante, M., Brunner, S., Pea, G., Fengler, K., Zuccolo, A., and Rafalski, A. 2005. Gene duplication and exon shuffling by helitron-like transposons generate intraspecies diversity in maize. Nat. Genet. 37: 997-1002.

Neiditch, M.B., Lee, G.S., Huye, L.E., Brandt, V.L., and Roth, D.B. 2002. The V(D)J recombinase efficiently cleaves and transposes signal joints. Mol. Cell 9: 871-878.

Ralston, E., English, J., and Dooner, H.K. 1989. Chromosomebreaking structure in maize involving a fractured $A c$ element. Proc. Natl. Acad. Sci. 86: 9451-9455.

Ranz, J.M., Casals, F., and Ruiz, A. 2001. How malleable is the eukaryotic genome? Extreme rate of chromosomal rearrangement in the genus Drosophila. Genome Res. 11: 230-239.

Ranz, J.M., Gonzalez, J., Casals, F., and Ruiz, A. 2003. Low occurrence of gene transposition events during the evolution 
of the genus Drosophila. Evolut. Int. J. Org. Evolut. 57: 13251335.

Richards, E.J., Goodman, H.M., and Ausubel, F.M. 1991. The centromere region of Arabidopsis thaliana chromosome 1 contains telomere-similar sequences. Nucleic Acids Res. 19: 3351-3357.

Schatz, D.G. 2004. V(D)J recombination. Immunol. Rev. 200: 5-11.

Soulas-Sprauel, P., Rivera-Munoz, P., Malivert, L., Le Guyader, G., Abramowski, V., Revy, P., and de Villartay, J.P. 2007. V(D)J and immunoglobulin class switch recombinations: A paradigm to study the regulation of DNA end-joining. Oncogene 26: $7780-7791$.

Wang, Q. and Dooner, H.K. 2006. Remarkable variation in maize genome structure inferred from haplotype diversity at the $b z$ locus. Proc. Natl. Acad. Sci. 103: 17644-17649.

Weil, C.F. and Kunze, R. 2000. Transposition of maize Ac/Ds transposable elements in the yeast Saccharomyces cerevisiae. Nat. Genet. 26: 187-190.

Weil, C.F. and Wessler, S.R. 1993. Molecular evidence that chromosome breakage by $D s$ elements is caused by aberrant transposition. Plant Cell 5: 515-522.

Zhang, J. and Peterson, T. 1999. Genome rearrangements by nonlinear transposons in maize. Genetics 153: 1403-1410.

Zhang, J. and Peterson, T. 2004. Transposition of reversed Ac element ends generates chromosome rearrangements in maize. Genetics 167: 1929-1937.

Zhang, J. and Peterson, T. 2005. A segmental deletion series generated by sister-chromatid transposition of $A c$ transposable elements in maize. Genetics 171: 333-344.

Zhang, J., Yu, C., Pulletikurti, V., Lamb, J., Danilova, T., Weber, D.F., Birchler, J., and Peterson, T. 2009. Alternative Ac/Ds transposition induces major chromosomal rearrangements in maize. Genes \& Dev. 23: 755-765.

Zhou, L., Mitra, R., Atkinson, P.W., Hickman, A.B., Dyda, F., and Craig, N.L. 2004. Transposition of hAT elements links transposable elements and V(D)J recombination. Nature 432: 9951001.

Zhang, J., Zhang, F., and Peterson, T. 2006. Transposition of reversed $A c$ element ends generates novel chimeric genes in maize. PLoS Genet. 2: e164. doi: 10.1371/journal.pgen. 0020164 


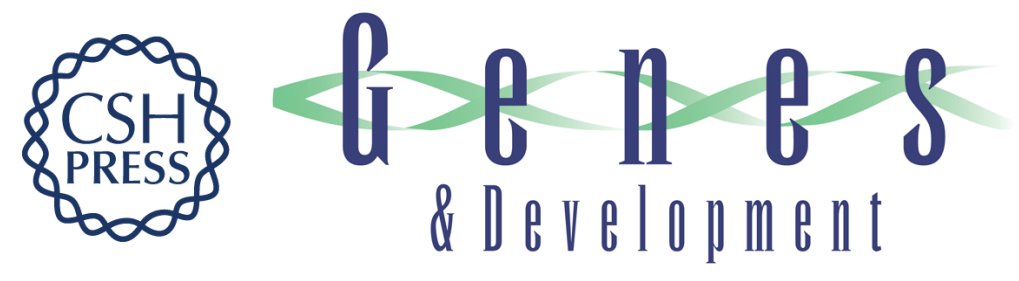

\section{Too many ends: aberrant transposition}

Clifford F. Weil

Genes Dev. 2009, 23:

Access the most recent version at doi:10.1101/gad.1801309

\section{Related Content Alternative Ac/Ds transposition induces major chromosomal rearrangements in maize Jianbo Zhang, Chuanhe Yu, Vinay Pulletikurti, et al. Genes Dev. March , 2009 23: 755-765 \\ References This article cites 42 articles, 20 of which can be accessed free at: http://genesdev.cshlp.org/content/23/9/1032.full.html\#ref-list-1 \\ Articles cited in: \\ http://genesdev.cshlp.org/content/23/9/1032.full.html\#related-urls \\ License \\ Email Alerting Receive free email alerts when new articles cite this article - sign up in the box at the top Service right corner of the article or click here.}

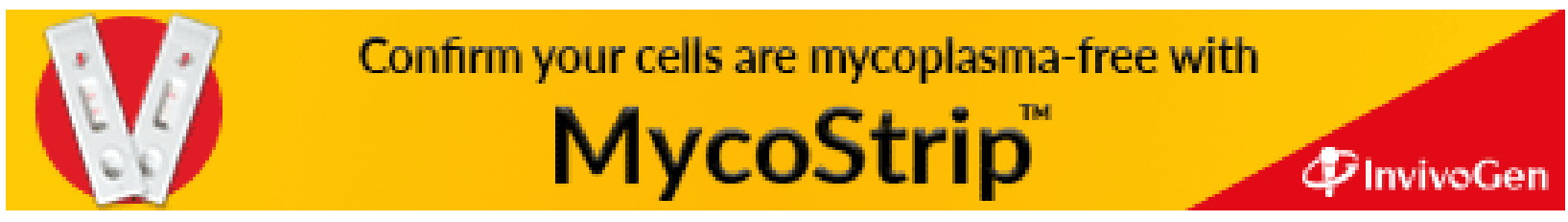

